\title{
Misinformation and \\ User-Generated content: Applying participatory journalism practices in fact-checking
}

\author{
Theodora Saridou*, Theodora Maniou ${ }^{\dagger}$ \\ and Andreas Veglis ${ }^{*}$ \\ *Media Informatics Lab, School of Journalism \& Mass Communication, \\ Aristotle University of Thessaloniki, 54124, Thessaloniki, Greece \\ ${ }^{\dagger}$ Department of Social \& Political Sciences, University of Cyprus, \\ L. Panepistimiou, 2109, Ag-lantzia, Nicosia, Cyprus \\ maniou.theodora@ucy.ac.cy
}

\begin{abstract}
In the evolving news media landscape, the proliferation of user-generated content in online news outlets and social media platforms has triggered changes in traditional processes and relationships. However, the coexistence of professional and amateur content raises a wide range of matters. Misinformation is one of the main problems faced by media organizations during the exploitation of huge amounts of data. In order to ensure the quality of the content, journalists use control methods and perform fact-checking not only on their own, but also by engaging users. By offering an examination of key issues arising from UGC research, this article seeks to focus on the application of participatory practices in fact-checking. In addition to more traditional methods, the webbased platform of Truly Media, which supports collaborative verification, is used as a case-study.
\end{abstract}

How to cite this book chapter:

Saridou, T., Maniou, T. and Veglis, A. 2020. Misinformation and User-Generated content: Applying participatory journalism practices in fact-checking. In: Loizides, F., Winckler, M., Chatterjee, U., Abdelnour-Nocera, J. and Parmaxi, A. (eds.) Human Computer Interaction and Emerging Technologies: Adjunct Proceedings from the INTERACT 2019 Workshops. Pp. 43-48. Cardiff: Cardiff University Press. DOI: https://doi.org/10.18573/book3.e. License: CC-BY 4.0. 


\section{Keywords}

Participatory Journalism • Fact-checking • Truly Media • Verification . User-Generated Content

\section{Introduction}

Over the recent decades, the predominance of user-generated content (UGC) in journalism has generated wide academic and entrepreneurial interest, since it has led to fundamental changes both in the news production process and in the journalists' relationship with the audience. Mainly in the form of text, photos, video and graphics [3], users' material is often invited and adopted by media organizations, which integrate non-professional contributions in their daily work routine, either directly or indirectly $[14,15]$. Thus, part of the citizens' activity takes place inside the walls of the established media outlets, where professional journalists and amateur users co-produce news within a mainstream platform in a participatory journalism context [2].

At the same time, news creation and dissemination is also shaped by the vast amounts of content that are dynamically produced on social media platforms. Networked media technologies are extending the ability of users to create and receive personalized news streams with social media becoming central to the way people experience news [10]. Instead of actively choosing to visit a news website or explicitly searching for a news topic, now news is passively found in posts shared from friends, family or news sources that users follow [4]. Journalists, on the other hand, use social networks to check on the activity of other news organizations, to look for breaking news events, find ideas for stories, keep in touch with their audience and gather information [28, p. 853].

As news becomes more social, journalists have to develop their skills and use digital tools in the service of tracing information, forensic examination, UGC dissemination and verification [11, 27]. Apart from traditional methods, though, part of the collection, management and validation is sometimes based on semantic web services. However, such methods are not widely adopted by organizations mainly due to problems related to the fragmented confrontation of the various cases and the maturation of the semantic technology [22].

\section{The need for fact-checking}

The challenge of exploiting a world of data stemming from a variety of sources is therefore posed to media organizations, as the incorporation of UGC often provokes threats to the ethical and legal established modus operandi $[21,24]$. At times of economic uncertainty, hyper-competition and diminishing accountability levels, when convergence is used as a cost-effective strategy fostering low-cost and spreadable news production [23], the hectic pace of 
news production process enhances the need of continuous monitoring and effective management.

Participatory spaces, however, are also considered vulnerable to the excessive use of inappropriate language, flaming, stereotyping, superficial discourse, hateful messages and incivility $[8,17,20]$. Research reveals that the potential for dark participation - ranging from misinformation and hate campaigns to individual trolling and cyberbullying is enormous, not only in comment sections controlled by the media themselves, but also on non-proprietary platforms, like Facebook, Youtube, Instagram or Twitter, where the negativity and toxic atmosphere can be equally bad and the deliberative quality is even lower [19]. The spreading of fake news, disinformation and conspiracy theories in UGC are forms of deviances as well, while malicious 'pseudo-users', troll armies and social bots have jarred confidence in even the fundamental assumption that user interaction is interaction with users [9].

In 2014, The Guardian publicly announced that a high number of strategically placed, manipulative pro-Russian user posts was detected in their comment sections. In a form of covert political propaganda, these 'participators' aimed to influence the Western public and (potentially) the journalists and there was evidence that linked these posts to the Russian government or at least their support groups [19]. Misinformation and propaganda can also take the form of hate campaigns that attack specific groups or individuals that symbolize these groups [18], while misinformation is also spread via social networks and short messaging services.

\section{Participatory practices for fact-checking}

In order to monitor UGC, media organizations utilize tools and build platforms which enable them to obtain, sort and disseminate news [12]. When pre-moderation is employed, journalists check every piece of UGC before published, achieving an adequate level of security, however not without high consumption of financial, human and time resources [24]. On the other hand, during post moderation, comments are first published and professionals intervene if a reason occurs; such techniques are nearly always accompanied by mandatory registration where users submit personal information in order to be accredited as commenters [24, p. 109], contributing in this way in the formation of hybrid salience [16].

In some cases, users are allowed to participate in the moderation process as well. When organizations apply reactive moderation, posts are checked only after the moderator receives an alert from a user [1]. Similarly [13], describe how the website 'Slashdot' distributed the moderation system to its user base: users achieved 'karma' (as the website itself describes it) through several activities. Each posted comment had a current score, from -1 to +5 . Users increased or decreased this score and chose from a list of descriptions, such as 'off topic', 'troll', 'insightful', 'funny' or 'overrated'. 
Except for concerns regarding resources, the individual moderation decision is also affected by newsroom routines, media organizations for which journalists work, the societal institutions and social system in which they operate, their personal experiences or even gut feelings [5, p. 60]. At the same time, although semantic technologies can help towards the direction of the simplification of UGC exploitation, such practices are not largely spread apart from several heterogeneous tools and applications. Moreover, it is noticed that tools and applications used by media organizations in UGC-driven platforms rely mostly on the integration with services provided by third parties, while professional journalists are still involved in many stages of the process [22, p. 286]. In a similar vein [26], argue that in the context of semantic web services it is hardly imaginable that isolated applications are able to serve successfully the users' ever growing requirements since the information normally available to human decision makers continues to grow beyond human cognitive capabilities. The rapid growth of such services also poses challenges on the field of interactions, for instance on social aspects connected with automatic transactions, especially the issue of trust within service discovery and composition [26].

In order to verify content, professionals often use web-based platforms or tools developed in collaborative projects which aim at finding and organizing information produced in social media and elsewhere. Truly Media (http://www.truly .media), for example, is a collaboration platform developed to support journalists and human rights workers in the verification of digital content, such as material residing in social networks. In order to address the misinformation ecosystem and what is often referred to as fake news, it supports its users to collaboratively assess the validity and accuracy of UGC that is distributed and shared via various means and networks. Based on the three main steps of detection, organization and verification, Truly Media applies a fully participatory practice in fact-checking. First, it provides to users the tools in order to find content from a variety of sources and bring all pieces of data together in one collection. Participants can afterwards organize their content and share their work and findings in real time with their colleagues. Finally, real-time collaborative verification is supported, through the exploitation of internal and third party tools.

\section{Conclusion}

The constantly produced UGC both in news websites and social media necessitates a thorough handling by media organizations. Fact-checking holds the leading position in struggling against misinformation and a long series of occurring problems. Participatory journalism can be an ally in this direction, mostly via platforms that reinforce collaboration between journalists and users and provide the tools for verifying the authenticity of the available information.

Overall, participation agitates not only the well-known notions of news production and consumption, but also traditional work practices as well. Gatekeeping turns to gatewatching [7] or even gateopening [6] and journalists do 
not define, but observe the information flow stemming from a variety of sources, receive UGC and construct a final product. It can thus be considered that users' involvement in fact-checking supports the core value of participatory journalism.

\section{References}

1. ABC (2014), Moderating user generated content-Guidance Note, http:// about.abc.net.au/reports-publications/moderating-user-generated -content-guidance-note/, last accessed 2019/4/20

2. Aitamurto, T.: Balancing between open and closed: Co-creation in magazine journalism. Digital Journalism, 1(2), 229-251 (2013).

3. Anderson, P.: What is Web 2.0? Ideas, technologies and implications for education. Technology \& Standards Watch, 1(1), 1-64 (2007).

4. Bentley, F., Quehl, K., Wirfs-Brock, J., \& Bica, M.: Understanding online news behaviors. In CHI Conference on Human Factors in Computing Systems Proceedings, Glasgow, Scotland: ACM, New York. doi: https://doi .org/10.1145/3290605.3300820 (2019).

5. Boberg, S., Schatto-Eckrodt, T., Frischlich, L., \& Quandt, T.: The moral gatekeeper? Moderation and deletion of user-generated content in a leading news forum. Media and Communication, 6(4): 58-69 doi: https://doi .org/10.17645/mac.v6i4.1493 (2018).

6. Boczkowski, J. B.: Digitizing the news: Innovation in online newspapers. Cambridge, MA: MIT Press (2005).

7. Bruns, A.: The active audience: transforming journalism from gatekeeping to gatewatching. In C. Paterson, \& D. Domingo (Eds.), Making online news: The ethnography of new media production (pp. 171-184). New York, NY: Peter Lang (2008).

8. Coe, K., Kenski, K., \& Rains, S. A.: Online and uncivil? Patterns and determinants of incivility in newspaper website comments. Journal of Communication, 64 (4): 658-679. doi: https://doi.org/10.1111/jcom.12104 (2014).

9. Frischlich, L., Boberg, S., \& Quandt, T.: Comment sections as targets of dark participation? Journalists' evaluation and moderation of deviant user comments. Journalism Studies, (latest articles). doi: https://doi.org/10.1080 /1461670X.2018.1556320 (2019).

10. Hermida, A., Fletcher, F., Korell, D. \& Logan, D.: Share, like, recommend. Journalism Studies, 13 (5-6): 815-824. doi: https://doi.org/10.1080/1461670X .2012 .664430 (2012).

11. Johnston, L.: Social news=Journalism evolution? Digital Journalism, 4 (7), 899-909, doi: https://doi.org/10.1080/21670811.2016.1168709 (2016).

12. Katsaounidou, A., Dimoulas, C., \& Veglis, A.: Cross-media authentication and verification: Emerging research and opportunities. Hershey, PA: IGI Global. doi: https://doi.org/10.4018/978-1-5225-5592-6 (2018).

13. Lampe, C., \& Resnick, P.: Slash(dot) and burn: Distributed moderation in a large online conversation space. In E. Dykstra-Erickson, \& M. Tscheligi 
(eds.), Proceedings of ACM CHI 2004 Conference on Human Factors in Computing Systems (pp. 543-550). Vienna, Austria: ACM New York (2004).

14. Maniou, T., \& Veglis, A.: 'Selfie Journalism: Current Practices in Digital Media. Studies in Media and Communication, 4 (1), 11-118, doi: https:// doi.org/10.11114/smc.v4i1.1637 (2016).

15. Maniou, T., Panagiotidis, K., \& Veglis, A.: The Politicization of Selfie Journalism: An empirical study to Parliamentary Elections. International Journal of E-Politics, 8 (2), 1-16, doi: https://doi.org/10.4018 /IJEP.2017040101 (2017).

16. Maniou, T., \& Bantimaroudis, P.: Hybrid Salience: Examining the role of traditional and digital media in the rise of the Greek radical left. Journalism, doi: https://doi.org/10.1177/1464884918796587 (2018).

17. Manosevitch, I.: User generated content in the Israeli online journalism landscape. Israel Affairs, 17 (3): 422-444. doi: https://doi.org/10.1080 /13537121.2011.584670 (2011).

18. Quandt, T., \& Festl, R. Cyberhate. In P. Rössler (ed.), The international encyclopedia of media effects (pp. 336-344). Malden: Wiley-Blackwell (2017).

19. Quandt, T.: Dark participation. Media and Communication, 6 (4): 36-48. doi: https://doi.org/10.17645/mac.v6i4.1519 (2018).

20. Santana, A. D.: Virtuous or vitriolic. The effect of anonymity on civility in online newspaper reader comment boards. Journalism Practice 8 (1): 18-33. doi: https://doi.org/10.1080/17512786.2013.813194 (2014).

21. Saridou, T., \& Veglis, A.: Participatory journalism policies in newspapers' websites in Greece. Journal of Greek Media and Culture, 2 (1): 85-101. doi: https://doi.org/10.1386/jgmc.2.1.85_1 (2016).

22. Saridou, T., Panagiotidis, K., Tsipas, N., \& Veglis, A.: Semantic tools for participatory journalism. Journal of Media Critiques, 4 (14): 281-294. doi: https://doi.org/10.17349/jmc118221 (2018).

23. Saridou, T., Spyridou, L. P., \& Veglis, A.: Churnalism on the rise? Digital Journalism, 5(8), 1006-1024. doi: https://doi.org/10.1080/21670811.2017 .1342209 (2017).

24. Singer, J. B., Hermida, A., Domingo, D., Heinonen, A., Paulussen, S., Quandt, T., Reich, Z., \& Vujnovic, M.: Participatory journalism. Guarding open gates at online newspapers. West Sussex, UK: Wiley-Blackwell (2011).

25. Truly Media, http://www.truly.media/, last accessed 2019/4/20

26. Vargas-Vera, M., Nagy, M., Zyskowski, D., Haniewicz, K., \& Abramowicz, W.: Challenges on semantic web services. In M. Cruz-Cunha, E. F. Oliveira \& A. J. Tavares (Eds.). Handbook of research on social dimensions of semantic technologies and web services (pp. 25-48). Hershey, PA: IGI Global. doi: https://doi.org/10.4018/978-1-60566-650-1

27. Veglis, A.: Education of journalists on ICTs issues and opportunities. Journal of Applied Journalism \& Media Studies, 2 (2): 265-279. doi: https:// doi.org/10.1386/ajms.2.2.265_1 (2013).

28. Weaver, D. H., \& Willnat, L.: Changes in U.S. Journalism. Journalism Practice, 10 (7): 844-855. doi: https://doi.org/10.1080/17512786.2016 .1171162 (2016). 